\title{
Follicular Granular Parakeratosis: A Case Report, Literature Review, and Proposed Classification
}

\author{
Phatcharawat Chirasuthat Suthep Chirasuthat Poonkiat Suchonwanit \\ Division of Dermatology, Faculty of Medicine, Ramathibodi Hospital, Mahidol University, Bangkok, Thailand
}

\section{Established Facts}

- Granular parakeratosis (GP) is a unique epidermal reaction representing an acquired disorder of keratinization.

- Follicular GP is a rare variant of GP which exclusively affects the follicular infundibulum without epidermal or eccrine ostium involvement.

\section{Novel Insights}

- Pathophysiology of follicular GP may relate to unusual contact reactions in the follicular infundibulum, resulting in an alteration of keratinocyte cornification.

- A classification of GP based on its distinct clinical manifestations and histopathological findings has been proposed.

\section{Keywords}

Facial keratotic papules · Facial papules · Granular parakeratosis $\cdot$ Hyperkeratosis $\cdot$ Keratinization disorder

\section{Abstract}

Granular parakeratosis (GP) is a distinctive acquired keratotic dermatosis that is usually presented with brownish-red hyperkeratotic papules and plaques in the intertriginous areas. Follicular involvement in GP could be either extending lesions from interfollicular epithelium or originating primarily from the follicular epithelium. The latter was named follicular GP and is considered an extremely rare condition. To our knowledge, there has been one reported case so far in the literature. We herein report the second case of follicular
GP in a 52-year-old Thai man presenting with multiple tiny filiform hyperkeratotic papules on his face 2 weeks after using anti-melasma cream. We also propose a classification of GP based on its distinct clinical manifestations and histopathological findings.

(c) 2021 S. Karger AG, Basel

\section{Introduction}

Granular parakeratosis (GP) is an uncommon acquired keratotic dermatosis characterized by brownishred papules that can coalesce into plaques [1]. The lesions mainly locate on intertriginous areas, most commonly on the axilla. Histopathological features consist of compact 

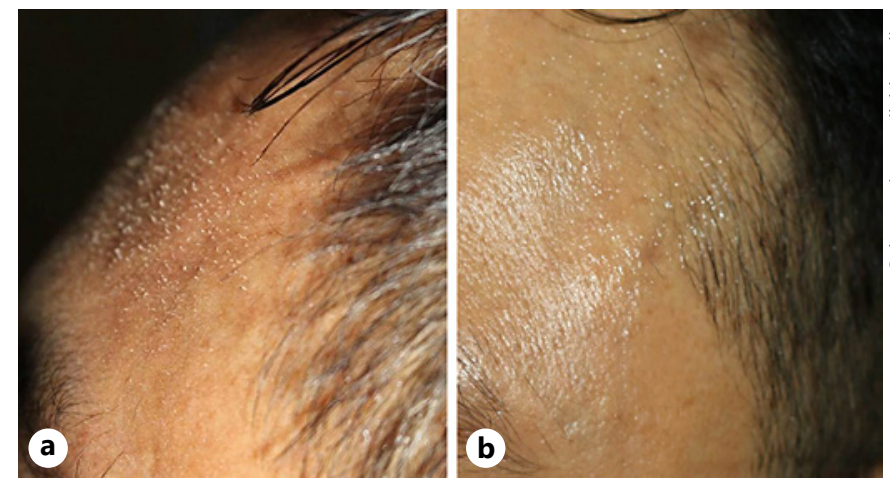

Fig. 1. Multiple discrete tiny filiform hyperkeratotic papules on forehead; before (a) and 2 weeks after discontinuing topical agents (b).

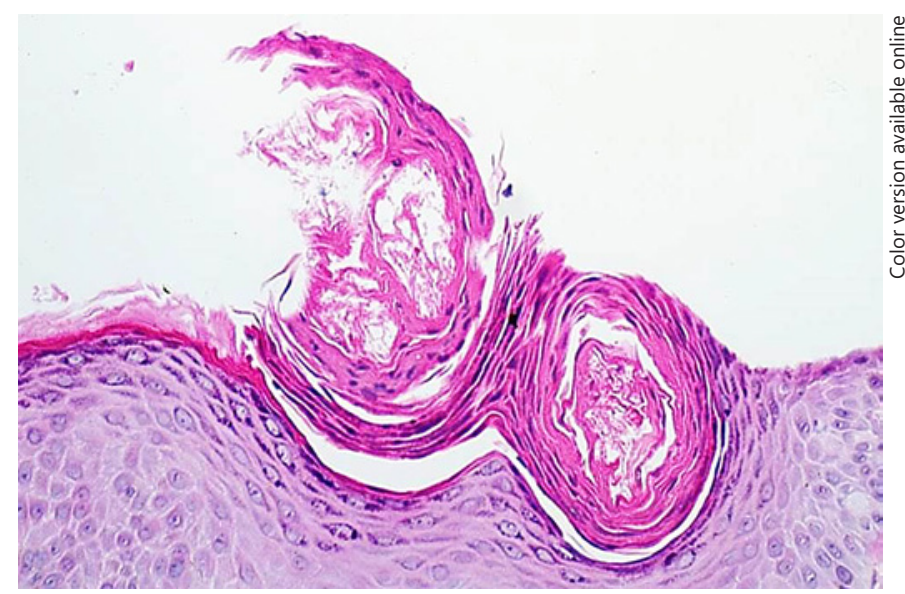

Fig. 3. Serial histopathological examination demonstrated dilated follicles with digitate parakeratotic plugging (hematoxylin-eosin, origin magnification, $\times 200$ ).

parakeratosis and retention of keratohyalin granules in the stratum corneum [2]. Follicular involvement in GP could be either extending lesions from interfollicular epithelium or originating primarily from the follicular epithelium. Remarkably, the latter is considered an extremely rare condition since it was once reported and named as follicular GP by Resnik and DiLeonardo [2]. They described an 83-year-old woman presenting with multiple keratotic papules on the trunk with no known aggravating factor [2]. We herein report the second case of follicular GP after using topical bleaching agents for the treatment of melasma. Furthermore, we propose a clas-

Follicular Granular Parakeratosis and Its Classification

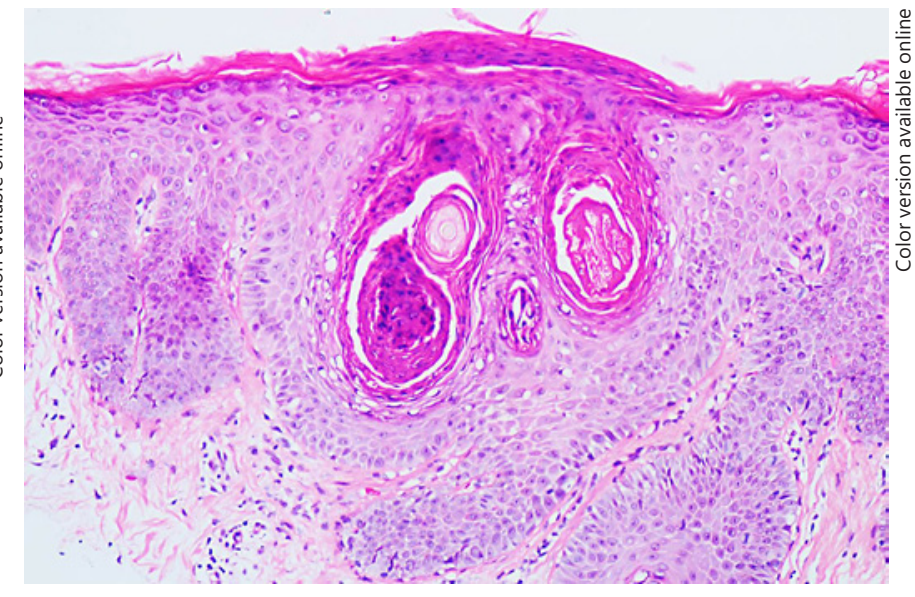

Fig. 2. Parakeratotic plugging in dilated follicular infundibulum and overlying follicular ostium (hematoxylin-eosin, origin magnification, $\times 20)$.

sification of GP based on clinical and histopathological characteristics reported in the current literature.

\section{Case Report/Case Presentation}

A 52-year-old Thai male manifested multiple digitate hyperkeratotic papules on his forehead and nose for 2 weeks. He felt that the lesions had appeared 2 weeks after applying topical agents to treat his melasma. The treatment comprised modified Kligman formulation ( $2 \%$ hydroquinone, $0.1 \%$ retinoic acid, and $0.01 \%$ triamcinolone acetonide), $7 \%$ arbutin, and a combination of vitamin $\mathrm{C}$ and licorice extraction. Burning and stinging were also reported. He denied previous illness before the development of the skin lesions. He had no underlying disease and was not taking any oral medication or supplements.

Physical examination revealed multiple discrete tiny hyperkeratotic filiform follicular papules on the forehead and nose (Fig. 1). The histopathological study demonstrated dilated follicles with digitate follicular hyperkeratosis and parakeratosis (Fig. 2, 3). There were no abnormalities in the interfollicular area. High-power resolution showed that the parakeratotic corneocytes contained basophilic granules similar to keratohyalin granules of the stratum granulosum. Based on the history, physical examination, and histopathological findings, the diagnosis of follicular GP was performed. The patient was informed to discontinue all topical agents, and emollient was substitutionally prescribed. Two weeks later, the lesions resolved spontaneously.

\section{Discussion/Conclusion}

GP is a unique epidermal reaction pattern that was originally described by Northcutt et al. [1], representing an acquired disorder of keratinization [3]. The disease 
Table 1. Proposed classification for GP

\begin{tabular}{|c|c|c|c|}
\hline Type & Clinical presentation & Pathophysiology & Histopathology \\
\hline $\begin{array}{l}\text { Intertriginous GP } \\
\text { (axillary GP) }[8-10,17]\end{array}$ & $\begin{array}{l}\text { Unilateral or bilateral, brownish-red papules } \\
\text { and plaques on the axillae } \\
\text { Additional intertriginous areas such as the } \\
\text { groin and inframammary fold may be } \\
\text { affected } \\
\text { Usually pruritus, or irritation }\end{array}$ & $\begin{array}{l}\text { Precise pathogenesis is unknown, but } \\
\text { contributing factors include personal } \\
\text { hygiene product use and mechanical } \\
\text { and chemical irritation }\end{array}$ & $\begin{array}{l}\text { Parakeratotic corneocytes contained } \\
\text { keratohyalin granules localizing to } \\
\text { the surface of the epidermis }(\mathrm{GP}) \\
\text { May extend into the adjacent hair } \\
\text { follicles }\end{array}$ \\
\hline Follicular GP [2] & $\begin{array}{l}\text { Multiple keratotic follicular papules on face, } \\
\text { upper abdomen, and intertriginous areas }\end{array}$ & $\begin{array}{l}\text { Repeated friction is supposed to be an } \\
\text { important causal factor in hot and } \\
\text { humid climatic region }\end{array}$ & $\begin{array}{l}\text { GP confining to the follicular } \\
\text { infundibulum } \\
\text { Sparing of epidermal or eccrine } \\
\text { ostium involvement }\end{array}$ \\
\hline Incidental GP [22-24] & $\begin{array}{l}\text { Clinical manifestations resemble primary } \\
\text { cutaneous conditions }\end{array}$ & $\begin{array}{l}\text { Reported in association with } \\
\text { dermatophyte infection, } \\
\text { dermatomyositis, and molluscum } \\
\text { contagiosum }\end{array}$ & $\begin{array}{l}\text { Granular parakeratoses that are } \\
\text { found in addition to other primary } \\
\text { cutaneous conditions }\end{array}$ \\
\hline
\end{tabular}

usually develops in middle-aged or older adults but may also be observed in children [4]. Women are affected more commonly than men [5], and it is more common in patients who are obese [6]. Clinical presentations include hyperkeratotic papules/plaques that are commonly distributed on the intertriginous areas, including axillae, groins, and mammary creases. It sometimes occurs on the face, back, or abdomen [1, 5, 7]. The histopathological characteristics show marked compact parakeratosis and remarkable retention of the keratohyalin granules in the stratum corneum [2]. Due to the commonly affected areas that are related to intertrigo, exogenous factors, such as personal hygiene products, chemical irritation, or mechanical factors, may contribute to altered proliferation and maturation of the epidermis [7-10]. Ultrastructural and immunohistochemical studies of the lesions demonstrate a primary defect in processing profilaggrin to filaggrin during keratinocyte cornification, failing to degrade keratohyalin granules and aggregate keratin filament [3].

The pathophysiology in our case remains uncertain, but unlike the first reported case [2], his medical history suggests the possibility of an unusual contact reaction to topical agents. In general, the topical medication has 3 routes of entry to the skin, counting transport through hair follicles, deliver via the sweat ducts, and pass directly across the stratum corneum [11]. Transdermal drug delivery depends on several factors, including drug dosage, lipophilicity, and molecular weight [12]. Hydrophilic agents such as hydroquinone, arbutin, or vitamin $\mathrm{C}$ would first contact with sebum, follicular debris, bacteria, and other exogenous materials coating the skin, then penetrate to the skin via their actual pathway through the hair follicle. A previous study suggested that topical hydroquinone could induce follicular inflammation by demonstrating the prominent expression of p56, a marker of cell proliferation, degeneration, and inflammation, in the hair follicles [13]. Furthermore, a high level of facial sebum contents filled in the follicular space can interfere with the follicular drug delivery, especially hydrophilic substances [14]. We hypothesize that the retention of the substances applied in the follicular infundibulum of individuals with underlying predisposition may induce the unusual contact reaction, resulting in an alteration of keratinocyte cornification.

As mentioned above, follicular involvement in GP could be either expanding lesions from interfollicular ep- 
ithelium or developing from the follicular epithelium. The present case showed clinical and histopathological features that were consonant with the diagnosis of follicular GP. First, the clinical features of tiny filiform hyperkeratotic papules correlated with digitate follicular hyperkeratosis from the histopathological findings. Second, the biopsy failed to demonstrate any evidence of other pathologic processes from the adjacent interfollicular epithelium. Last, the lesions developed after using topical agents, which may be an aggravating factor, and improved after cessation. Several treatments, including topical corticosteroids, vitamin D analogs, retinoids, ammonium lactate, cryotherapy, oral isotretinoin, and antifungals are promising therapies based on previous case reports and series $[1,3,15,16]$. However, a spontaneous resolution was observed in the present case and previous reports [2].

Since 1991, several cases of GP have been reported in a variety of clinical and histopathological presentations, and emerging evidence suggests that the condition is an epidermal reaction pattern to various etiologies in susceptible individuals rather than a disease. We have intensively reviewed the literature and would like to propose a classification of GP according to its distinct clinical manifestations and histopathological findings (Table 1) [2, 8-10, 17-24].

We present a rare case of exclusive follicular involvement of GP on the face, which may be associated with contact reaction to topical agents. We also introduce a classification of GP on purpose that, hopefully, will lead to better characterization for this condition. Clinicians should consider follicular GP in the differential diagnosis of multiple filiform hyperkeratotic lesions, especially on the face or intertriginous area [25].

\section{Statement of Ethics}

The patient provided written informed consent to perform all necessary investigations, to take clinical photographs, and use them for research purposes and publication. The patient understood that her name and initial will not be published and due efforts will be made to conceal her identity. This case report was conducted ethically in accordance with the World Medical Association Declaration of Helsinki.

\section{Conflict of Interest Statement}

The authors have no conflicts of interest to declare.

\section{Funding Sources}

The authors have no funding sources to declare.

\section{Author Contributions}

All named authors meet the International Committee of Medical Journal Editors (ICMJE) criteria for authorship for the manuscript, take responsibility for the integrity of the work as a whole, and have given final approval to the version to be published.

\section{References}

1 Northcutt AD, Nelson DM, Tschen JA. Axillary granular parakeratosis. J Am Acad Dermatol. 1991 Apr;24(4):541-4.

2 Resnik KS, DiLeonardo M. Follicular granular parakeratosis. Am J Dermatopathol. 2003 Oct;25(5):428-9.

3 Metze D, Rütten A. Granular parakeratosis: a unique acquired disorder of keratinization. J Cutan Pathol. 1999 Aug;26(7):339-52.

4 Neri I, Patrizi A, Guerrini V, Fanti PA. Granular parakeratosis in a child. Dermatology. 2003;206(2):177-8.

5 Scheinfeld NS, Mones J. Granular parakeratosis: pathologic and clinical correlation of 18 cases of granular parakeratosis. J Am Acad Dermatol. 2005 May;52(5):863-7.

6 Ding CY, Liu H, Khachemoune A. Granular parakeratosis: a comprehensive review and a critical reappraisal. Am J Clin Dermatol. 2015 Dec;16(6):495-500.
7 Joshi R, Taneja A. Granular parakeratosis presenting with facial keratotic papules. Indian J Dermatol Venereol Leprol. 2008 JanFeb;74(1):53.

8 Martorell A, Sanmartín O, Hueso-Gabriel L, Guillén C. Granular parakeratosis: disease or reactive response? Actas Dermosifiliogr. 2011 Jan;1(102):72-4.

9 Wallace CA, Pichardo RO, Yosipovitch G, Hancox J, Sangueza OP. Granular parakeratosis: a case report and literature review. $\mathrm{J} \mathrm{Cu}-$ tan Pathol. 2003 May;30(5):332-5.

10 Patrizi A, Neri I, Misciali C, Fanti PA. Granular parakeratosis: four paediatric cases. $\mathrm{Br} \mathrm{J}$ Dermatol. 2002 Nov;147(5):1003-6.

11 Prausnitz MR, Mitragotri S, Langer R. Current status and future potential of transdermal drug delivery. Nat Rev Drug Discov. 2004 Feb;3(2):115-24.
12 Choy YB, Prausnitz MR. The rule of five for non-oral routes of drug delivery: ophthalmic, inhalation and transdermal. Pharm Res. 2011 May;28(5):943-8.

13 Owolabi JO, Fabiyi OS, Adelakin LA, Ekwerike MC. Effects of skin lightening cream agents: hydroquinone and kojic acid, on the skin of adult female experimental rats. Clin Cosmet Investig Dermatol. 2020 Apr;13:283.

14 Meidan VM, Docker M, Walmsley AD, Irwin WJ. Low intensity ultrasound as a probe to elucidate the relative follicular contribution to total transdermal absorption. Pharm Res. 1998 Jan;15(1):85-92.

15 Mehregan DA, Vandersteen P, Sikorski L, Mehregan DR. Axillary granular parakeratosis. J Am Acad Dermatol. 1995 Aug;33(2 Pt 2): 373-5.

16 Webster CG, Resnik KS, Webster GF. Axillary granular parakeratosis: response to isotretinoin. J Am Acad Dermatol. 1997 Nov;37(5 Pt 1):789-90. 
17 Mehregan DA, Thomas JE, Mehregan DR. Intertriginous granular parakeratosis. J Am Acad Dermatol. 1998 Sep;39(3):495-6.

18 Wang L, Yang L, Wang G, Gao T. Granular parakeratosis of eccrine ostia. Am J Dermatopathol. $2008 \mathrm{Feb}$;30(1):65-6.

19 Yang JH, Lee HM, Noh TK, Won CH, Chang S, Lee MW, et al. Granular parakeratosis of eccrine ostia. Ann Dermatol. 2012 May;24(2): 203-5.
20 Reichel M. Hypergranulotic dyscornification: a distinctive histologic pattern of maturation of epidermal epithelium present in solitary keratoses. Am J Dermatopathol. 1999 Feb; 21(1):21-4.

21 Resnik KS, Kantor GR, DiLeonardo M. Granular parakeratotic acanthoma. Am J Dermatopathol. 2005 Oct;27(5):393-6.

22 Resnik KS, Kantor GR, DiLeonardo M. Dermatophyte-related granular parakeratosis. Am J Dermatopathol. 2004 Feb;26(1):70-1.
23 Pock L, Hercogová J. Incidental granular parakeratosis associated with dermatomyositis. Am J Dermatopathol. 2006 Apr;28(2):147-9.

24 Pock L, Cermáková A, Zipfelová J, Hercogová J. Incidental granular parakeratosis associated with molluscum contagiosum. Am J Dermatopathol. $2006 \mathrm{Feb} ; 28(1): 45-7$.

25 Leerunyakul K, Chirasuthat P, Suchonwanit P. A case report of idiopathic follicular hyperkeratotic spicules and literature review. Case Rep Dermatol. 2019 Oct 2;11(3):278-85. 